\title{
Computational drug ZINPIP-Analog an ultimate solution to cure conserved domains of mutant EGFR, ALK and BRAF Proteins in NSCLC
}

\author{
*Anum Munir ${ }^{1}$, Sajid Khan ${ }^{1}$ and Shumaila Azam² \\ ${ }^{1}$ Department of Bioinformatics, Government Post Graduate College, Mandian, Abbottabad 22010, Pakistan \\ ${ }^{2}$ Department of Bioinformatics, Muhammad Ali Jinnah University, Islamabad 44000, Pakistan
}

\begin{abstract}
Mutations in different genes such as EGFR, ALK and BRAF results in non-small cell Lung cancer (NSCLC). The most ordinarily discovered EGFR mutations in patients with NSCLC are deletion in exon 29 or in 21. Mutations initiate the tyrosine kinase activity of EGFR and are connected with the affectability to small molecules results in the formation of NSCLC. The missense mutations of BRAF have been detected in exon 11 and 15. Mutation of ALK occurs as a result of small inversion. The primary objective of study was to design novel chemical compound to block the targeted sites for receptor proteins, present on cells surface which control the growth or stop the proliferation of cancer cells. After screening large amount of data we have designed Novel Insillico drug compound Zinpip analog for NSCLC that blocks the EGFR, ALK, and BRAF. In docked complexes ALA, LYS, and ARG were common interacting residues for EGFR and ALK. ALA and GLY were common for ALK and BRAF mutant protein and Ligand complex interaction. ALA was common among all interactions. Molecular formula of Zinpip analog completely satisfies the Lipinski rules of five. It shows less side effects and long resistance against for non-small cell lung cancer. We conclude that our drug Zinpip analog is superior to commercial drugs available in market. As it is non-toxic in nature and has no side effects.
\end{abstract}

Key Words: Zinpip analog, EGFR, ALK, BRAF, NSCLC.

\section{INTRODUCTION}

Lung malignancy includes uncontrolled cell development in tissues of the lung which may prompt metastasis. The greater part of essential lung cancer growths are carcinomas, gotten from epithelial cells. Generally DNA damages in the middle of typical cell division because of natural impacts of radon gas, asbestos, and growth changes resulting from chemicals, for example, uranium, nickel chromates, coal items, mustard gas, chloromethyl ethers, fuel, and diesel deplete (Ettinger et al., 2010). The carcinoma splits far from mass of cells and invade different tissues of lung. After its impact, the whole lung contains the tumor cells and stops their normal capacity of function (Choi et al., 2010; Rogerio and Carolyn, 2012; SIGN, 2007).

Around one out of each eight individuals diagnosed with small cell lung tumor, $10 \%$ to $15 \%$ of all lung disease are small cells lung carcinomas (SCLC) (NCI, 2012). The small cell lung carcinoma and non-small cell lung carcinoma are dealt with in an unexpected way non-small cell lung carcinomas (NSCLC) are every now and then treated with surgery, while SCLC shows better response to chemotherapy and radiation (American cancer society, 2014). Around 7 out of 8 individuals diagnosed with NSCLC. It has slower development rate. NSCLC most generally results from hereditary changes and is a driving reason for passing away of men and ladies. Approximately, $85 \%$ of lung tumors are non-small cell lung carcinomas (NCI, 2012).

Basic indications of lung cancer are weight reduction, hacking up blood, midsection torment, dyspnea, persevering hack, windedness, wheezing, rapines, shoulder torment, and tiredness (SIGN, 2007). The
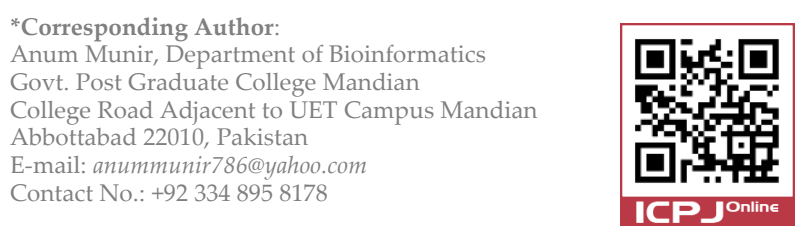

medications for lung malignancy include surgery, chemotherapy, radiations, combined medicines, and targeted treatments. Chemotherapy is attained by blend of medications; targeted treatment is intended to assault cell growth by appending or blocking the targets, which show up on the cell surface. In many cases the targeted medications may not react to illness and malignancy may return, medications may produce harmful impacts on body and might have serious reactions (Rogerio and Carolyn, 2012).

Mutations in different genes such as EGFR, ALK, and BRAF results in non-small cell lung cancer. The most commonly found EGFR mutations in patients with NSCLC are deletion in exon 29 or mutation in exon 21 (Ettinger et al., 2010; Toyooka et al., 2005). EGFR pathway is the main regulator of cell function and cancer development. Common BRAF transversion mutations occur at exon 15. The missense mutations of BRAF have been detected in exon 11 and exon 15 (American cancer society, 2014; Baskaran et al., n.d.; Taha, 2012; Marchetti et al., 2011). Mutation of ALK occurs as a result of small inversion within the short arm of chromosome 2 (Choi et al., 2010). Up till now EGFR, BRAF and ALK fusion genes are most broadly included in the advancement of lung adenocarcinoma and NSCLC (Bronte et al., 2010).

\section{MATERIALS AND METHODS}

After screening NSCLC causing genes from gene cards database, we selected 120 mutated ids of EGFR, 55 of ALK and 29 of BRAF proteins form research collaboratory for structural bioinformatics (pdb). Structural alignmnet was done to find conserved domains of proteins and new protein structures were prepared in Phyre 2 tool. We screened huge measure of medication databases, examined most active functional rings and atoms exhibit in those medications and designed new drug compound comprising of those functional rings and atoms with the assistance of bioinformatics apparatus ACD/ChemSketch. 


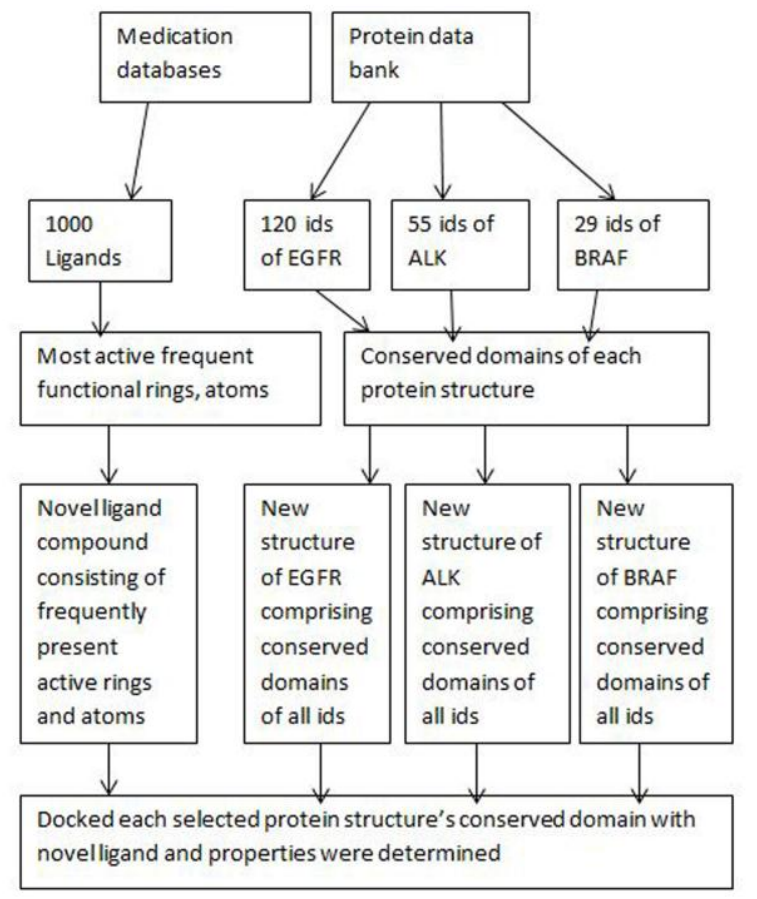

Figure 1: methodology applied for the preparation of protein structures and drug compound.

It is the most effective, generally useful synthetic drawing and designing tool. It can change over SMILES documentations to Structure and the other way around (Baskaran et al., 2008). After designing, we suggested the name of our novel drug compound as Zinpip analog. Then Zinpip analog was checked for toxicity and ADMET properties (Chase et al., 2014) and docked to proteins, after docking, QSAR and pharmacophore models were prepared in discovery studio software. The methodology applied is shown in figure 1 .

Zinpip inhibitor for EGFR, ALK, and BRAF has composition C (56.58\%), H (7.55\%), Cl (7.59\%), N $(18.00 \%), \mathrm{O}(10.28 \%), \log \mathrm{P}$ ranges from $0.58-1.86$. It completely satisfies the Lipinski's rule of five, and has appropriate ADMET properties. The compound Zinpip

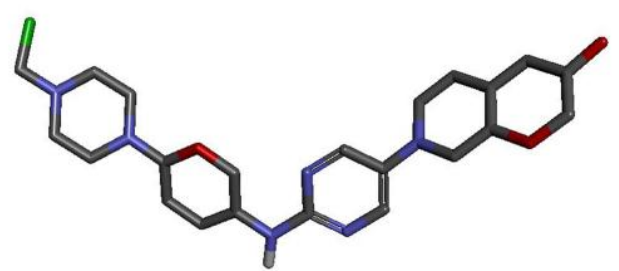

Figure 2: Zinpip analog for EGFR, ALK, and BRAF proteins.

analog is shown in figure 2 .

The most ordinarily discovered EGFR mutations in patients with NSCLC are deletion in exon 29 or in 21. Mutations initiate the tyrosine kinase activity of EGFR and are connected with the affectability to the small molecules that results in the formation of NSCLC (Ettinger et al., 2010; Toyooka et al., 2005). The conserved domain of EGFR protein family is shown in figure 3.

Substantial transformations in BRAF have to be found in $30 \%$ to $40 \%$ of non-small cell lung cancers. Normal transversion mutations happen at exon 158 (Taha, 2012). The missense mutations of BRAF have been detected in exon 11 and exon 15. BRAF codes for a nonreceptor serine/threonine kinase (Marchetti et al., 2011). The substantial mutation of BRAF in C1786G promotes to L596V in the NSCLC cell line (Chase et al., 2014; Zahra et al. 2013; Pennell, 2012; Suleiman et al., 2013; Bronte et al., 2010; Hartenfeller et al., 2004; Heigener, 2012; Davies et al., 2002). The conserved domain of BRAF protein is shown in figure 4.

Mutation of ALK has to be found in $4 \%$ to $5 \%$ of non-small cell lung cancers, occurs as result of small inversion with in the short arm of chromosome 2 . The ALK experiences demerization through the collaboration between the snaked loop area inside ALK region of monomers and results in the initiation of ALK and produces its onco-hereditary action, along snacked loop area NSCLC occurs in body (Choi et al., 2010; P.A et al., 2005). The conserved domain of ALK protein family is shown in figure 5.

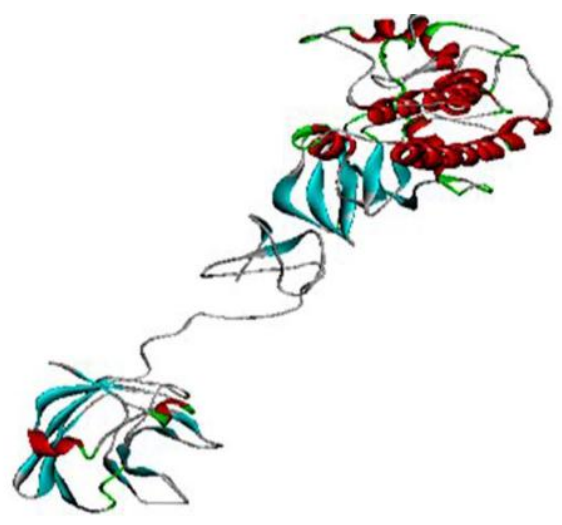

Figure 4: Conserved domain of BRAF's protein family.

Figure 3: Conserved domain of EGFR's protein family. 
Table 1: Properties of inhibitor compound based on Lipinski rule of 5 .

\begin{tabular}{|ll|}
\hline Molecular weight & $446.586-467.0047$ \\
H-bond acceptors & 8 \\
H-bond donors & 2 \\
Log P & $0.58-1.86$ \\
Molar refractivity & $123.13 \pm 0.3 \mathrm{~cm}^{3}$ \\
Rotatable bonds & 5 \\
No. of atoms & 66 \\
Polar surface area & $86.22 \mathrm{~A}^{2}$ \\
Molar volume & $355.8 \pm 3.0 \mathrm{~cm}^{3}$ \\
Index of refraction & $1.608 \pm 0.02$ \\
Density & $1.312 \pm 0.06 \mathrm{~g} / \mathrm{cm}^{3}$ \\
\hline
\end{tabular}

\section{RESULTS}

Docking permits the researchers to screen a database of compounds and predicts the strongest inhibitors in light of different scoring functions (Kobayashi et al., 2005). QSAR models of complexes were determined and an ADMET property was figured in light of the Lipinski's Rule of Five, ADMET properties of Zinpip were determined. ADMET refers to absorption, distribution, metabolism, and excretion -toxicity in pharmacokinetics (Hammerman et al., 2013; Biedunkiewicz et al., 2014; Riquet et al., 2014; Chauhan et al., 2014).

In our selected proteins; the aspartic acid (D) serves as an active site. The molecule binding to a receptor inhibits its function and thus acts as drug (Marchetti et al., 2011). The Zinpip analog was docked with EGFR protein and interacting residues were: ALA86, ARG108, ASN110, LEU144, LYS212, ARG252, LYS253, and ALA289. EGFR protein and zinpip analog complex shows better interactions, best fits in pocket of protein and does not leave the complex which shows steadiness of Zinpip analog. The best docking results of EGFR and Zinpip drug complex is shown in figure $6 a$ and $6 \mathrm{~b}$.

The Zinpip analog compound docked with ALK and interacting atoms are: ARG1120, GLY1121, LEU1122, HIS1124, ALA1126, PHE1127, ASP1203, LYS1205, and ARG1253. At the point when the Ligand goes into the protein, a few atoms of the Ligand bond to the passage amino acids. The inhibitors of the high activity just have these characters, which adequately restrains the protein (Chen, 2012). The docking result of ALK and Zinpip complex is shown in figure $7 \mathrm{a}$ and $7 \mathrm{~b}$.

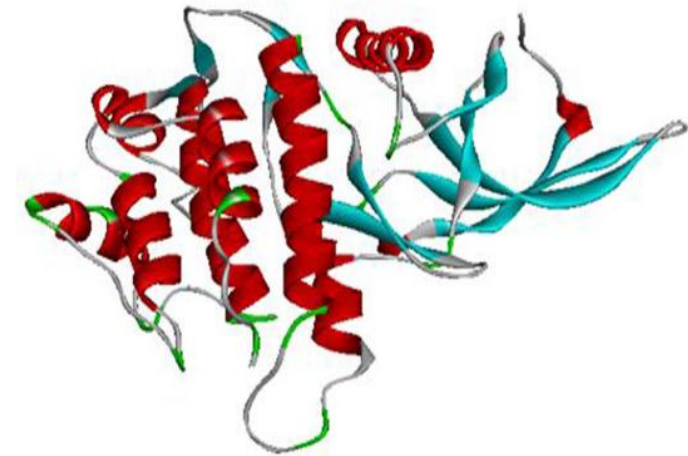

Figure 5: Conserved domain of ALK's protein family.

Zinpip analog docked with BRAF and interacts with ALA481, CYS532, ASN580, and GLY593. For every protein and its inhibitor we selected the ligand atoms in the binding site, calculated RMSD values between their predicted and observed positions. A Ligand residue is thought to be in the binding site if any of its atoms is within $10 \AA$ of an atom on the receptor (P.A, 2005). The docking result of BRAF and Zinpip is shown in figure 8a and $8 \mathrm{~b}$.

The alteration of the molecular structure of drug frequently prompts drugs with higher molecular weight, more rings, more rotatable bonds, and a higher lipophilicity that might affect the quality of drugs (Ammi et al., 2015) but our Ligand compound Zinpip analog fulfills all the properties of Lipinski rule of five that are shown in table 1.

We have predicted toxicity levels of compound and dose distribution frequency by Protox drug toxicity prediction server. The toxicity level of our drug compound Zinpip analog is in class 6, it is harmless and nontoxic class. There are no toxic fragments in Zinpip analog structure. The compound present in class six is non-poisonous and might create few impacts if gulped more than $\left(\mathrm{LD}_{50}>5000 \mathrm{mg} / \mathrm{kg}\right.$ ). Doses are frequently given as LD50 values in $\mathrm{mg} / \mathrm{kg}$ body weight. LD 50 is an

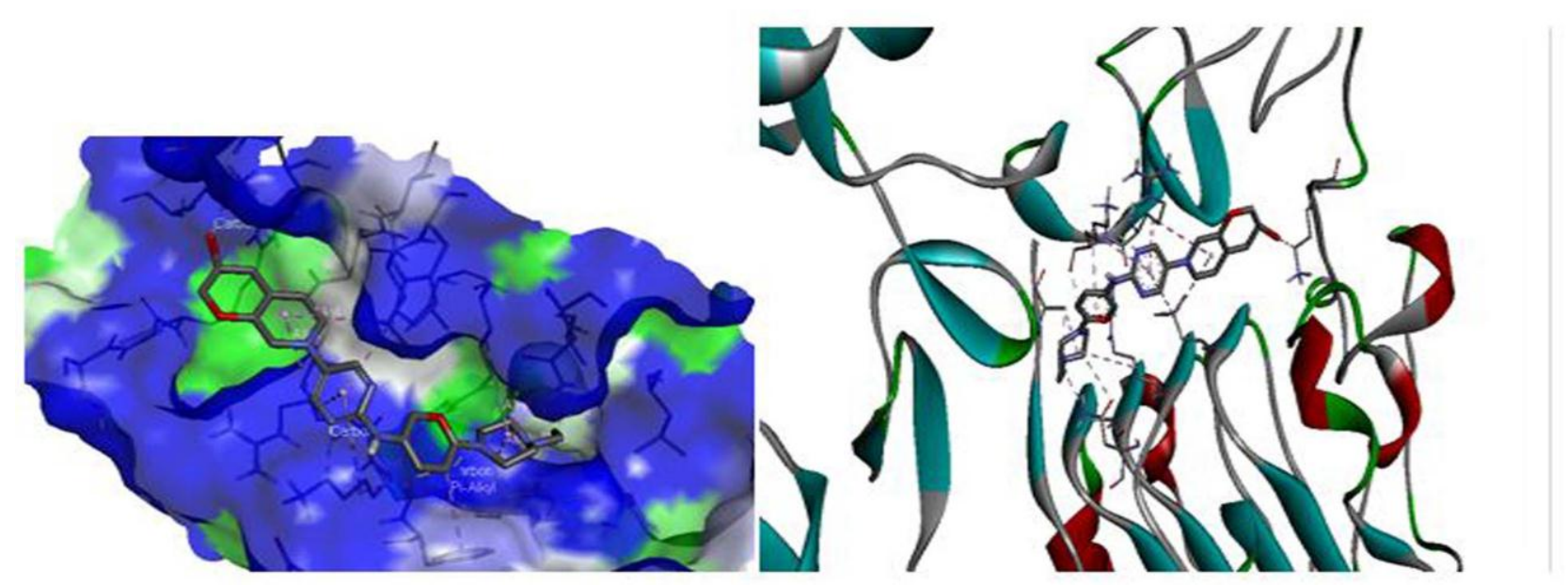

Figure 6a: EGFR's conserved domain and zinpip analog complex. 


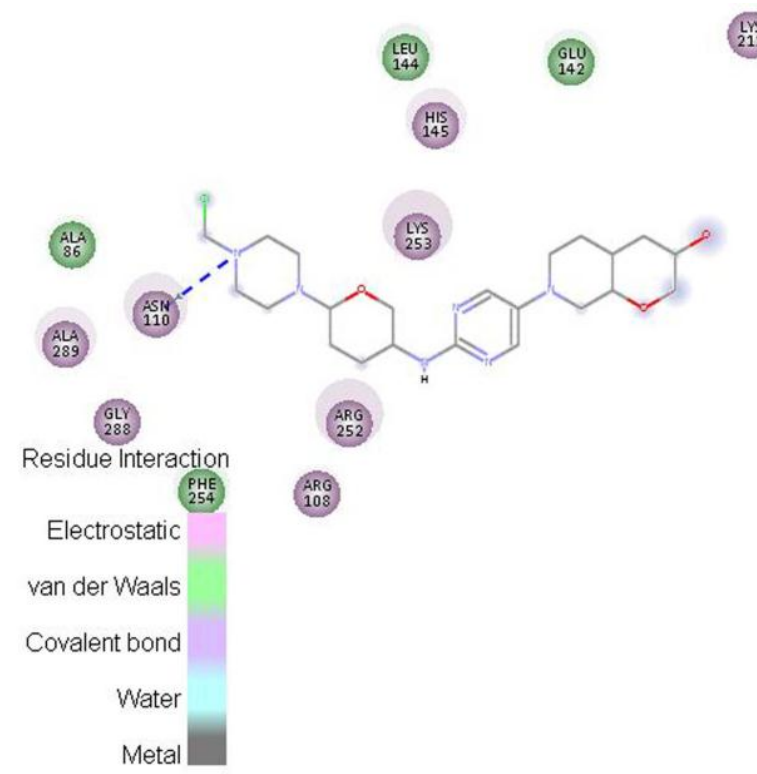

Figure 6b: Ligand and interacting residues in EGFR, ligand docked complex.

average deadly measurement (Kurnatowski et al., 2014; Sculier et al., 2015). Zinpip analog might produce some effects if gulped at very high frequency of dose. The toxicity class was characterized by the globally harmonized system of classification of labeling of chemicals.

\section{DISCUSSION}

Three-dimensional structure predictions of most genes/proteins recommends that it might be utilized further to comprehend the potential component of lung tumor development and part of these proteins in bringing up irregularities. Additionally, it opens the new door of medication planning for the better distinguishing proof of potential medication inhibitors (Zahra et al., 2013; Bronte et al., 2010). One of the medications planning routines incorporate building of Ligand generally eluded as receptor-based drug design. The key point of such technique is formation of novel structures, not contained in any database can be proposed (Taha, 2012). We have adopted such approach and tried to produce insilico novel drug compound Zinpip analog for our selected proteins. Molecules designed Insilico display sought properties as well as manageable to compound amalgamation and have handy quality for drug disclosure ventures (Hartenfeller, 2004).

The endorsed drugs in NSCLC are the Gefitinib and Erlotinib for patients with EGFR mutation in NSCLC, both drugs show symptoms as diarrhea, whizzing, and tiredness (Heigener, 2012). The vast majority of drugs at present cannot utilize as standard treatment for early stages of NSCLC. Doctors can use Gefitinib as a first treatment for NSCLC that is prominently exceptional or has spread. Patients having mutations in ALK protein demonstrated no advantages from the utilization of Erlotinib (Suleiman et al., 2013). Gefitinib is used if the tumor cells have EGFR receptors (Kobayashi et al., 2005). It has demonstrated clearly that the drug Gefitinib has been utilized to target the human epidermal growth factor receptor. Gefitinib on docking with EGFR delivers an energy estimation of 248 and 268 respectively (Baskaran et al., 2008). Our drug inhibitor zinpip analog also target EGFR delivered better energy values than Gefitinib. The Gefitinib don't demonstrate any reaction to the patients having twofold mutations of EGFR (Li et al., 2015). We have prepared such compound that also shows response to twofold mutations.

Most patients having NSCLC comprising of mutations in the EGFR gene attains response to EGFR inhibitors such as Afatinib, after at least 12 week, again symptoms develop. Afatinib neglects to enhance the general survival (Pennell, 2012; Dai and Tan, 2015). Erlotinib is commonly used to target EGFR mutated nonsmall cell lung cancer. There are two impediments of Erlotinib. In the first place, it can be utilized only for single lung cell line. Second, different parts like vasculature, immunological cells also influenced (Li et al., 2015; Sculier et al., 2015).

Vemurafenib is a common inhibitor used for BRAF mutations. Regular symptoms identified with vemurafenib are arthralgia, rash, exhaustion, alopecia, keratoacanthoma or squamous-cell carcinoma, photosensitivity, queasiness, and loose bowels (Sanchez et al., 2013).

Docetaxel plus cisplatin with paclitaxel plus carboplatin are used in combined chemotherapy to cure nonsmall cell lung cancer, but it numerically results in only

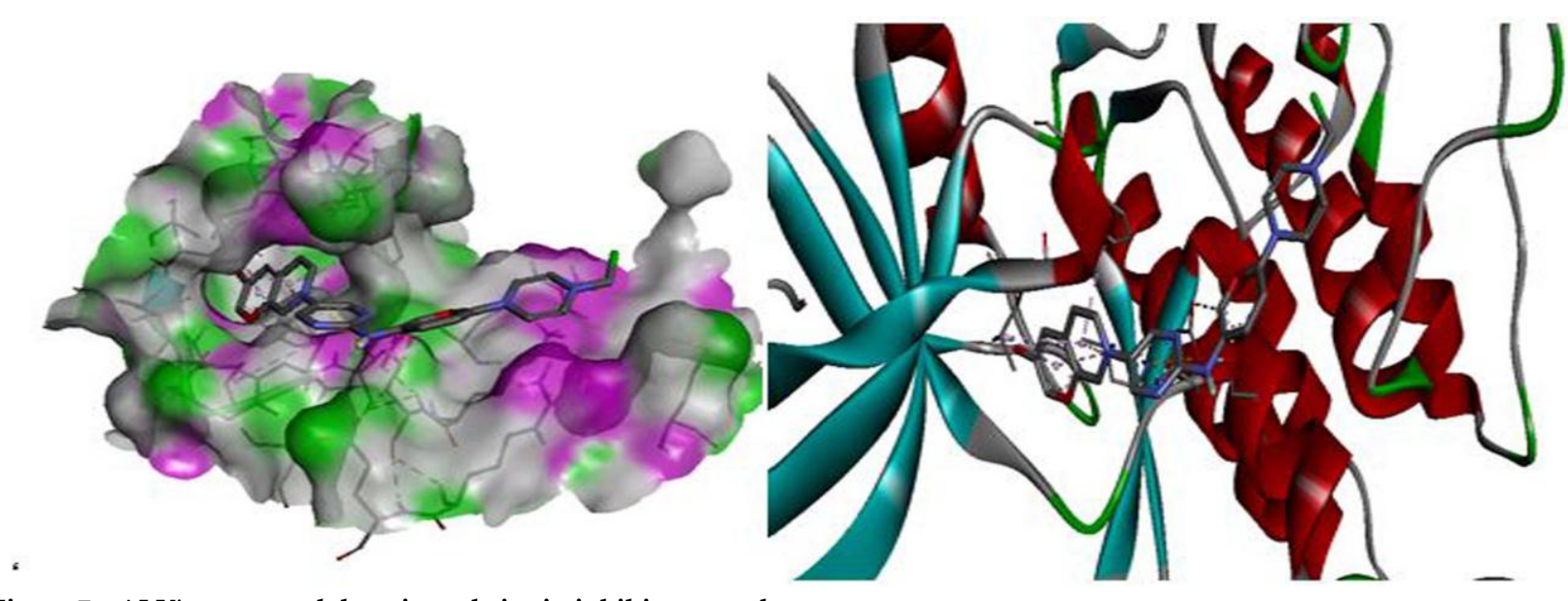

Figure 7a: ALK's conserved domain and zinpip inhibitor complex. 


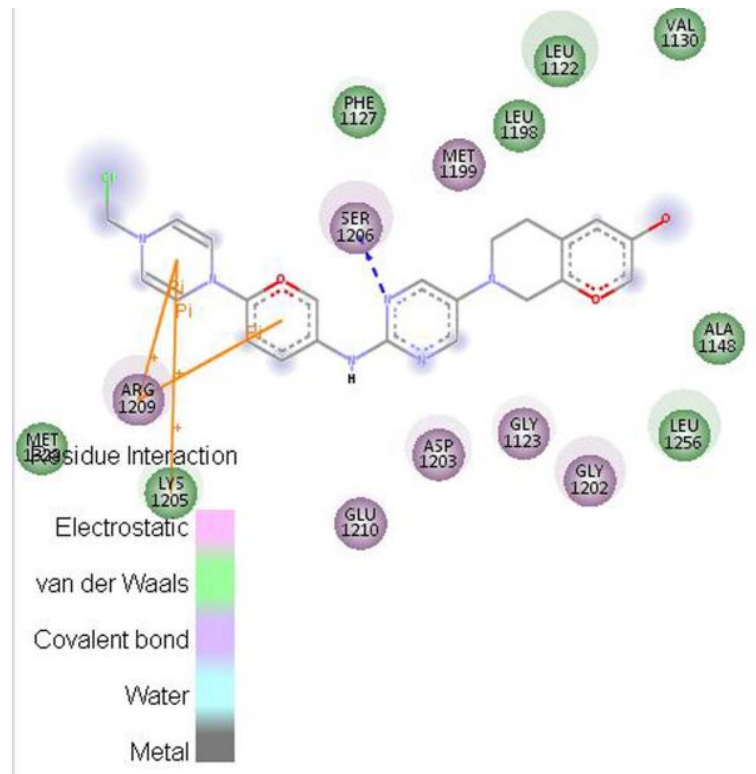

Figure 7b: Ligand and interacting residues in ALK, ligand docked complex.

one year survival of NSCLC patient (Khodadad et al., 2014). A few chalcone structures have been designed and tried on human lung carcinoma cell lines with promising effects against proliferation of cancer, results at micromolar to nanomolar fixations. Notwithstanding, less is thought about the toxic impacts of these drugs on lung carcinoma cell lines and cells responses to these drug at the time of exposure. Chalcone structures are highly toxic compounds and have many side effects (Nakhjavani et al., 2014).

Zinpip analog will show better results than these medications and will help in better survival of patients. Our designed drug zinpip analog targets cancer's specific genes, proteins, or the tissue environment that aids in survival of cancer. The drug compound Zinpip analog affirms associations with EGFR, ALK, and BRAF proteins and hinders their irregular activities.

\section{CONCLUSION}

In our research work we have taken epidermal growth factor receptor (EGFR), anaplastic lymphoma kinase (ALK), and BRAF protein, recognized their conserved

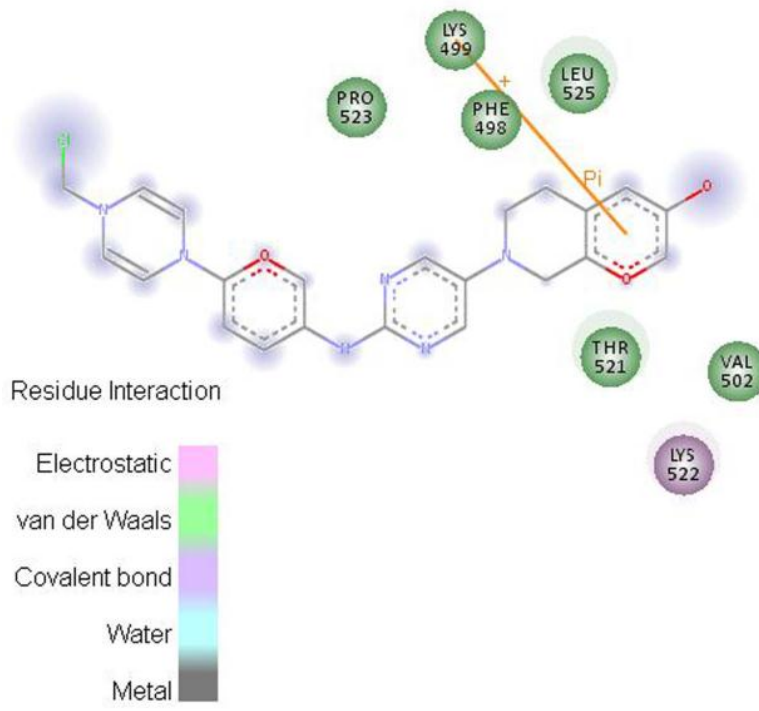

Figure 8b: Ligand and interacting residues in BRAF, ligand docked complex.

domains, designed the inhibitor molecule Zinpip analog for them, and docked with these three selected proteins, we investigated that Zinpip analog compound best fits in the pockets of proteins which demonstrates its soundness and affirms its drug likeness properties. The amino acid residue ALA was common among all protein interacting pockets. The vast majority of the monetarily accessible medications may abuse couple of the properties of Lipinski rule of five but our drug Zinpip analog is completely satisfying the Lipinski rules of five values having Log P 0.58-1.86, molar refractivity $123.13 \pm 0.3 \mathrm{~cm}^{3}$, H-bond acceptors and donor 8 and 2, respectively. We checked the toxicity levels, and health effects of drugs mentioned in discussion; that are used to cure NSCLC, we conclude that our drug Zinpip analog is superior to these commercial drugs available in market. As it is non-toxic in nature and has no side effects. In future this research work can be further utilized as a part of clinical trials to test its adequacy and social advantages.
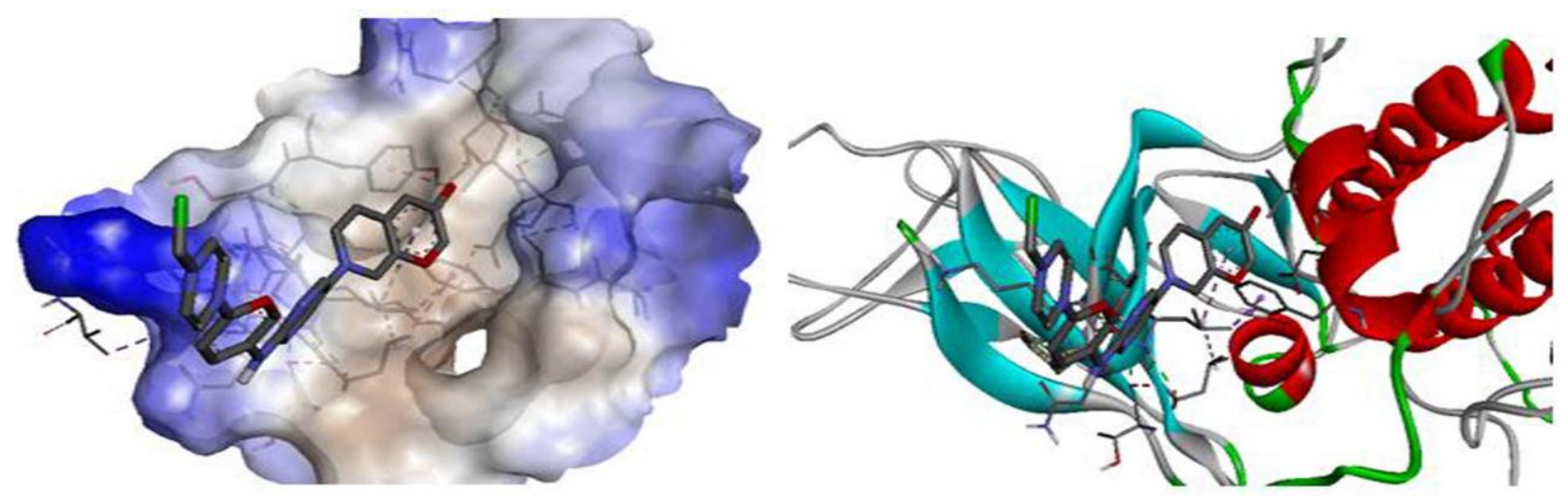

Figure 8a: BRAF's conserved domain and zinpip complex. 


\section{ACKNOWLEDGEMENT}

Our research exploration work is unique and has not been submitted in any journal yet. None of the author has challenging conflicts of interest. We are grateful to Dr. Inzaar Abbasi, who suggested the name Zinpip for our drug compound.

\section{AUTHORS' CONTRIBUTION}

The research outline was arranged by Sajid Khan. Anum Munir carried out whole research process, designed the research methodology, gathers data, analyzed and interprets results, performed all activities in the completion of research process. And, also wrote Research paper under the supervision of Sajid Khan

Shumaila Azam helped in analyzing results. Research paper drafts were checked and proof reading was performed by Sajid Khan. Shumaila Azam also gave suggestions in the rearrangement of paper, and in the submission of paper manuscript. Everyone read and approved the research paper final manuscript.

\section{REFERENCES}

American Cancer Society. Cancer Facts \& Figures 2014. Atlanta, Ga: American Cancer Society; 2014.

Ammi R., De Waele J., Willemen Y., Van Brussel I., Schrijvers D.M., Lion E., et al. (2015) Poly(I:C) as cancer vaccine adjuvant: Knocking on the door of medical breakthroughs. Pharmacol Ther. 146:120-131. [DOI]

Baskaran, C., Bai, V. R., Kumaran, K., \& Kumar, K. M. (2008). Compute aided drug designing (CADD) for EGFR protein Controlling lung cancer. Drugs, 14(15), 16.

Biedunkiewicz A., Kowalska K., Schulz L., Stojek K., Dynowska M., Ejdys E., et al. Mycological monitoring of selected aquatic ecosystems in the context of epidemiological hazards. Drinking water. Ann Parasitol. 2014; 58(3):191-198.

Bronte, G., Rizzo, S., La Paglia, L., Adamo, V., Siragusa, S., Ficorella, C., et al. (2010). Driver mutations and differential sensitivity to targeted therapies: a new approach to the treatment of lung adenocarcinoma. Cancer Treatment Reviews, 36, S21-S29. [DOI]

Chase SM, Crabtree BF, Stewart EE, Nutting PA, Miller WL, Stange KC, et al. (2014) Coaching strategies for enhancing practice transformation. Fam Pract. PMid:25281823

Chauhan J.S., Dhanda S.K., Singla D., Agarwal S.M., Raghava G.P.S. (2014) QSAR-Based Models for Designing Quinazo-

line/Imidazothiazoles/Pyrazolopyrimidines Based Inhibitors against Wild and Mutant EGFR. PLoS One, 9(7):e101079. [DOI]

Chen P-Y. (2012) Computational Virtual Screening towards Designing Novel Anticancer Drugs. Virtual Screening; 91.

Choi, Y. L., Soda, M., Yamashita, Y., Ueno, T., Takashima, J., Nakajima, T., et al. (2010). EML4-ALK mutations in lung cancer that confer resistance to ALK inhibitors. New England Journal of Medicine, 363(18), 17341739. [DOI] PMid:20979473

Dai X., Tan C. (2015) Combination of MicroRNA Therapeutics with Smallmolecule Anticancer Drugs: Mechanism of Action and Co-delivery Nanocarriers. Adv Drug Deliv Rev, 81:184-197. [DOI] PMid:25281917

Davies, H., Bignell, G. R., Cox, C., Stephens, P., Edkins, S., Clegg, S., et al. (2002). Mutations of the BRAF gene in human cancer. Nature, 417(6892), 949-954. [DOI]

Ettinger, D. S., Akerley, W., Bepler, G., Blum, M. G., Chang, A., Cheney, R. T., Yang, S. C. (2010). Non-Small Cell Lung Cancer. Journal of the National Comprehensive Cancer Network, 8(7), 740-801. PMid:20679538
Hammerman, P.S., Sos, M.L., Ramos, A.H., Xu, C., Dutt, A., Zhou, W., et al. (2011) Mutations in the DDR2 kinase gene identifies a novel therapeutic target in squamous cell lung cancer. Cancer Discov., 1(1):78-89. [DOI]

Hartenfeller, M. (2004). Development of a computational method for reaction-driven de novo design of drug like compounds, [Link]

Heigener, D. F. (2012). The Use of Biomarkers to Guide Treatment Decisions in Non-small-cell Lung Cancer. Clinical Chemistry, 30(6th) [Link]

Khodadad, K., Khosravi, A., Esfahani-Monfared, Z., Karimi, S., \& Seifi, S (2014). Comparing Docetaxel Plus Cisplatin with Paclitaxel Plus Carboplatin in Chemotherapy-Naïve Patients with Advanced NonSmall-Cell Lung Cancer: a Single Institute Study. Iranian Journal of Pharmaceutical Research: IJPR, 13(2), 575. PMid:25237353

Kobayashi, S., Boggon, T. J., Dayaram, T., Jänne, P. A., Kocher, O., Meyerson, M., et al. (2005). EGFR mutation and resistance of nonsmall-cell lung cancer to gefitinib. New England Journal of Medicine, 352(8), 786-792. [DOI]

Kurnatowski P, Moqbil S, Kaczmarczyk D. Signs, symptoms and the prevalence of fungi detected from the oral cavity and pharynx of radiotherapy subjects with head and neck tumors, and their susceptibility to chemotherapeutics. Ann Parasitol. 2014; 58(3):207-213.

Li, Y.-Y., Lam, S.-K., Zheng, C.-Y., \& Ho, J. C.-M. (2015). The Effect of Tumor Microenvironment on Autophagy and Sensitivity to Targeted Therapy in EGFR-Mutated Lung Adenocarcinoma. Journal of Cancer, 6(4), 382-386. [DOI]

Marchetti, A., Felicioni, L., Malatesta, S., Sciarrotta, M. G., Guetti, L., Chella, A., et al. (2011). Clinical Features and Outcome of Patients With Non-Small-Cell Lung Cancer Harboring BRAF Mutations. Journal of Clinical Oncology, 29(26), 3574-3579. [DOI]

Nakhjavani, M., Zarghi, A., \& Shirazi, F. H. (2014). Cytotoxicity of selected novel chalcone derivatives on human breast, lung and hepatic carcinoma cell lines. Iranian Journal of Pharmaceutical Research: IJPR, 13(3), 953. PMid:25276196

National cancer institute (2012). Lung cancer. National institute of health 12-1553.

Pennell, N. A. (2012). Treating acquired resistance to EGFR-tyrosine kinase inhibitors: still a work in progress. Translational Lung Cancer Research 1(2), 149. PMid:25806172

Riquet M., Arame A., Fabre E. (2014) N2 involvement in lung cancer: the Danaïdes' barrel. Eur J Cardiothorac Surg. pii: ezu369 [DOI]

Rogerio C. L., Carolyn M. (2012). Cancer care national Inc. New York. NY 10001. [Link]

Sánchez-Torres, J. M., Viteri, S., Molina, M. A., \& Rosell, R. (2013). BRAF mutant non-small cell lung cancer and treatment with BRAF inhibitors. Translational Lung Cancer Research, 2(3), 244-250. PMid:25806238

Scottish Intercollegiate Guidelines Network. (2007). Lung cancer: for patients. Edinburgh: SIGN.

Sculier J-P, Berghmans T, Meert A-P. Advances in target therapy in lung cancer. Eur Respir Rev. 2015 Mar 1; 24(135): 23-29. [DOI]

Suleiman A.A., Nogova L., Fuhr U. (2013) Modeling NSCLC Progression Recent Advances and Opportunities Available. AAPS J.15(2):542-550. [DOI]

Taha, M. O. (2012). Virtual screening. Croatia: Intech. [DOI]

Toyooka, S., Kiura, K., Mitsudomi, T., \& others. (2005). EGFR mutation and response of lung cancer to gefitinib. N Engl J Med, 352(20), 2136. [DOI]

Zahra, S. N., Khattak, N. A., \& Mir, A. (2013). Comparative modeling and docking studies of p16ink4/Cyclin D1/Rb pathway genes in lung cancer revealed functionally interactive residue of RB1 and its functional partner E2F1. Theoretical Biology and Medical Modelling, 10(1), 1. [DOI] 